\title{
GlaxoSmithKline responds to the consensus statement from the American Diabetes Association and the European Association for the Study of Diabetes
}

\author{
P. Ambery - A. R. Cobitz
}

Received: 20 January 2009 /Accepted: 22 January 2009/Published online: 4 March 2009

(C) Springer-Verlag 2009

\section{Abbreviation \\ FDA Food and Drug Administration}

To the Editor: GlaxoSmithKline regrets the recommendation [1] of the recent consensus statement from the American Diabetes Association and the European Association for the Study of Diabetes against the use of rosiglitazone for treatment of type 2 diabetes, because it is contrary to scientific evidence.

The evidence regarding a possible association of rosiglitazone with increased risk of cardiovascular ischaemic morbidity remains inconclusive. Data from clinical trials assessing cardiovascular outcomes are inconsistent with hypotheses of increases in the rates of myocardial ischaemia or death that have arisen from meta-analyses. No long-term clinical trial has confirmed an increased risk of cardiovascular ischaemia with rosiglitazone. Moreover, data from two large head-to-head clinical trials-A Diabetes Outcome Progression Trial (ADOPT) [2] and the interim report of the Rosiglitazone Evaluated for Cardiac Outcomes and Regulation of Glycemia in Diabetes (RECORD) trial [3] show that, apart from the well-documented risk of heart

P. Ambery $(\bowtie)$

Cardiovascular, Metabolic and Musculoskeletal

Centre of Excellence, GlaxoSmithKline,

Uxbridge, Middlesex UB11 1BT, UK

e-mail: phil.d.ambery@gsk.com

\section{A. R. Cobitz}

Clinical Development, Medicines Development

Centre-Metabolic, GlaxoSmithKline,

Philadelphia, PA, USA failure with thiazolidinediones, rosiglitazone has a cardiovascular risk profile comparable to the recommended tier 1 glucose-lowering medicines, metformin and sulfonylurea.

The consensus statement contains multiple unexplained inconsistencies regarding the evidence underlying its conclusions and recommendations. Data from long-term clinical trials, which provide gold-standard evidence, sometimes appear to receive less weight than conclusions from hypothesisgenerating meta-analyses. This circumstance is difficult to understand, particularly in light of a recent comment by the corresponding author of the consensus statement [4] that 'the vagaries of meta-analyses make them unreliable'.

Furthermore, the consensus statement cites data in an inconsistent manner. Meta-analyses critical of rosiglitazone are mentioned repeatedly, while analyses reporting no increase in cardiovascular ischaemic risk with rosiglitazone versus other established glucose-lowering medications are overlooked (such as those performed by Lago et al. [5] and the US Food and Drug Administration [FDA] [6]). A metaanalysis [7] that reported a statistically significant increase in a composite endpoint of cardiovascular hospitalisation or mortality with the combination of sulfonylureas and metformin - a tier 1 recommended option-is not mentioned in the consensus statement.

The authors of the consensus statement write that 'the overarching principle in selecting a particular intervention will be its ability to achieve and maintain glycaemic goals' [1]. Rosiglitazone has been shown to provide glycaemic control for up to 5 years - significantly longer than the most commonly used oral glucose-lowering medications, sulfonylurea and metformin [2]. GlaxoSmithKline strongly believes that rosiglitazone has a place in the therapeutic armamentarium for type 2 diabetes when used appropriately. 
Major regulatory agencies, including the FDA and the European Medicines Agency, have thoroughly reviewed all available safety and efficacy data for rosiglitazone in recent months and maintained the availability of rosiglitazone to patients.

\section{References}

1. Nathan D, Buse J, Davidson MB et al (2009) Medical management of hyperglycaemia in type 2 diabetes: a consensus algorithm for the initiation and adjustment of therapy. A consensus statement from the American Diabetes Association and the European Association for the Study of Diabetes. Diabetologia 52:17-30

2. Kahn SE, Haffner S, Heise MA et al (2006) Glycemic durability of rosiglitazone, metformin, or glyburide monotherapy. N Engl J Med $355: 2427-2443$
3. Home PD, Pocock SJ, Beck-Nielsen H et al (2007) Rosiglitazone evaluated for cardiovascular outcomes - an interim analysis. $\mathrm{N}$ Engl J Med 357:28-38

4. Nathan DM (2008) Glycemic management of type 2 diabetes: how tight is right and how to get there. Arch Intern Med 168:2064-2066

5. Lago RM, Singh PP, Nesto RW (2007) Congestive heart failure and cardiovascular death in patients with prediabetes and type 2 diabetes given thiazolidinediones: a meta-analysis of randomised clinical trials. Lancet 370:1129-1136

6. US Food and Drug Administration (2007) FDA briefing document. Joint meeting of the Endocrinologic and Metabolic Drugs Advisory Committee and the Drug Safety and Risk Management Advisory Committee, July 30, 2007. Available from www.fda.gov/ohrms/ dockets/ac/07/briefing/2007-4308b1-02-fda-backgrounder.pdf, accessed 9 January 2009

7. Rao AD, Kuhadiya N, Reynolds K, Fonseca VA (2008) Is the combination of sulfonylureas and metformin associated with an increased risk of cardiovascular disease or all-cause mortality? A meta-analysis of observational studies. Diabetes Care 31:16721678 